\title{
GABA in the central amygdaloid nucleus modulates the electrolyte excretion and hormonal responses to blood volume expansion in rats
}

\author{
L.O. Margatho, L.L.K. Elias and J. Antunes-Rodrigues \\ Departamento de Fisiologia, Faculdade de Medicina de Ribeirão Preto, Universidade de São Paulo, \\ Ribeirão Preto, SP, Brasil \\ Correspondence to: J. Antunes-Rodrigues, Departamento de Fisiologia, FMRP, USP, Av. Bandeirantes, \\ 3900, 14049-900 Ribeirão Preto, SP, Brasil \\ Fax: +55-16-3633-0017. E-mail: antunes@fmrp.usp.br
}

\begin{abstract}
We investigated the involvement of GABAergic mechanisms of the central amygdaloid nucleus (CeA) in unanesthetized rats subjected to acute isotonic or hypertonic blood volume expansion (BVE). Male Wistar rats bearing cannulas unilaterally implanted in the CeA were treated with vehicle, muscimol $(0.2 \mathrm{nmol} / 0.2 \mu \mathrm{L})$ or bicuculline $(1.6 \mathrm{nmol} / 0.2 \mu \mathrm{L})$ in the CeA, followed by isotonic or hypertonic BVE ( 0.15 or $0.3 \mathrm{M} \mathrm{NaCl}, 2 \mathrm{~mL} / 100 \mathrm{~g}$ body weight over $1 \mathrm{~min}$ ). The vehicle-treated group showed an increase in sodium excretion, urinary volume, plasma oxytocin (OT), and atrial natriuretic peptide (ANP) levels compared to control rats. Muscimol reduced the effects of BVE on sodium excretion (isotonic: $2.4 \pm 0.3$ vs vehicle: $4.8 \pm 0.2$ and hypertonic: $4.0 \pm 0.7$ vs vehicle: $\left.8.7 \pm 0.6 \mu \mathrm{Eq} \cdot 100 \mathrm{~g}^{-1} .40 \mathrm{~min}^{-1}\right)$; urinary volume after hypertonic BVE $(83.8 \pm 10$ vs vehicle: $255.6 \pm 16.5$ $\mu \mathrm{L} \cdot 100 \mathrm{~g} \mathrm{~g}^{-1} \cdot 40 \mathrm{~min}^{-1}$ ); plasma OT levels (isotonic: $15.3 \pm 0.6$ vs vehicle: $19.3 \pm 1$ and hypertonic: $26.5 \pm 2.6 \mathrm{vs}$ vehicle: $48 \pm 3 \mathrm{pg} /$ $\mathrm{mL}$ ), and ANP levels (isotonic: $97 \pm 12.8$ vs vehicle: $258.3 \pm 28.1$ and hypertonic: $160 \pm 14.6$ vs vehicle: $318 \pm 16.3 \mathrm{pg} / \mathrm{mL}$ ). Bicuculline reduced the effects of isotonic or hypertonic BVE on urinary volume and ANP levels compared to vehicle-treated rats. However, bicuculline enhanced the effects of hypertonic BVE on plasma OT levels. These data suggest that CeA GABAergic mechanisms are involved in the control of ANP and OT secretion, as well as in sodium and water excretion in response to isotonic or hypertonic blood volume expansion.
\end{abstract}

Key words: Central amygdaloid nucleus; Natriuresis; Urine output; Oxytocin; Atrial natriuretic peptide

Presented at the IV Miguel R. Covian Symposium, Ribeirão Preto, SP, Brazil, May 23-25, 2008.

Research supported by FAPESP (\#03/00327-8) and CNPq (\#14544-0). L.O. Margatho is the recipient of a fellowship from FAPESP (\#05/60889-5).

Received October 30, 2008. Accepted January 15, 2009

\section{Introduction}

Blood volume expansion (BVE) induces several regulatory responses by reflex mechanisms, including inhibition of sympathetic outflow to the kidney, heart, and blood vessels, reduction of renin and vasopressin secretion, and increased atrial natriuretic peptide (ANP) and oxytocin (OT) release that leads to diuresis and natriuresis (1-3).

The central amygdaloid nucleus $(\mathrm{CeA})$ is an important constituent of central pathways that regulate cardiovascular control as well as hormonal and behavioral responses in order to minimize and correct sodium deficits (4). In turn, $\mathrm{CeA}$ projections to the hypothalamus and the brainstem have been shown to be involved in blood pressure control (5). Electrical and chemical stimulation of the CeA in anesthetized rats reduces arterial pressure and heart rate (4) and also alters the development of spontaneous hypertension in rats (6). Lesions and chemical stimulation of the 
amygdaloid complex inhibit sodium intake (7). Rats with lesions of the $\mathrm{CeA}$ also fail to ingest $0.5 \mathrm{M} \mathrm{NaCl}$ in response to activation of the brain angiotensin or to systemic mineralocorticoid administration that produces a strong $\mathrm{NaCl}$ appetite in controls (8). Zardetto-Smith et al. (9) demonstrated that electrolyte lesions of the $\mathrm{CeA}$ and bed nucleus of the stria terminalis (BNST) cause a significant reduction in the sodium intake induced by systemic administration of yohimbine (an $\alpha-2$ adrenoceptor antagonist) or by sodium depletion induced by furosemide.

Godino et al. (10) showed that volume-expanded rats had a significant increase in Fos-ir neurons in the CeA and the BNST. In addition, Margatho et al. (11) showed an increase of Fos expression in retrogradely labeled cells of the $\mathrm{CeA}$ and BNST, adding new information concerning the specific groups of neurons involved in the body volume regulation that have direct or monosynaptic connections with the lateral parabrachial nucleus in response to isotonic BVE.

GABA is a dominant inhibitory neurotransmitter in the brain known to play an important role in the central sympathetic and cardiovascular regulation. Intracerebroventricular (icv) injections of GABA agonists decrease arterial blood pressure, heart rate, and sympathetic nerve activity, while icv injections of GABA antagonists, such as bicuculline methiodide, markedly increase arterial blood pressure and heart rate due to an increase in sympathetic nerve activity (12). The CeA contains large populations of GABAergic neurons and its ionotropic receptor $\mathrm{GABA}_{A}$ is blocked by low doses of bicuculline and is positively modulated by benzodiazepines, anesthetics, and barbiturates (13). Ciriello and Roder (14) reported that microinjections of GABA or bicuculline significantly attenuated the magnitude of the depressor and bradycardic responses elicited by selective activation of $\mathrm{CeA}$ neurons by L-glutamate (an excitatory amino acid) in anesthetized rats.

A number of neuroendocrinological studies have indicated a central GABAergic action in the control of anterior pituitary hormone secretion (15). Moreover, GABAergic nerve terminals have been observed in neurosecretory nerve endings in the neurohypophysis (16), suggesting an important role for the inhibitory neurotransmitter GABA in regulating the activity of oxytocin neurons (17). In addition, several limbic structures, including various parts of the amygdaloid nuclei, have been shown to exert an inhibitory influence on the electrical activity of supraoptic and paraventricular magnocellular neurosecretory cells recorded in vivo (18).

However, the contribution of amygdala GABA systems to the responses induced by BVE has not been demonstrated. Thus, the aim of the present study was to deter- mine the participation of the GABAergic system by the administration of muscimol or bicuculline into the $\mathrm{CeA}$ in the control of the sodium excretion, urinary volume, plasma levels of OT and ANP in response to BVE.

\section{Material and Methods}

\section{Animals}

Male Wistar rats (280-350 g) from the Central Animal Facility of the Ribeirão Preto Campus, University of São Paulo, were housed in individual stainless steel cages in a room with controlled temperature $\left(23 \pm 2^{\circ} \mathrm{C}\right)$ and a 12:12$\mathrm{h}$ light:dark cycle (light on at 7:00 am), with free access to food pellets and tap water. The experiments were performed between 9:00 am and 1:00 pm. All procedures for care and use of animals were approved by the Committee for Animal Use of the School of Medicine of Ribeirão Preto, University of São Paulo (\#009/2006).

\section{CeA cannulation}

Rats were anesthetized with 2,2,2-tribromoethanol (Aldrich Chemical Co., USA; $200 \mathrm{mg} / \mathrm{kg}$ body weight) and placed in a Kopf stereotaxic apparatus (model 900). The skull was leveled between bregma and lambda. Stainless steel guide cannulas ( $0.4 \mathrm{~mm} I D, 0.6 \mathrm{~mm}$ OD) were unilaterally implanted into the $\mathrm{CeA}$ using the following coordinates: $2.2 \mathrm{~mm}$ caudal to the bregma, $4.5 \mathrm{~mm}$ lateral to the midline and $7.2 \mathrm{~mm}$ below the dura mater. The tips of the guide cannulas were targeted to be placed $2 \mathrm{~mm}$ above each $\mathrm{CeA}$. Cannulas were fixed to the cranium using dental acrylic resin and two jeweller's screws. A 30-gauge metal wire filled the cannulas, except during the injections. After surgery, the rats received a prophylactic injection of penicillin $(20,000$ units, im) and were allowed to recover for 7 days, during which they were handled daily and habituated to the removal of the obturator of the guide cannula and to the gavage procedures.

\section{Histology of the CeA}

After the experiments, animals received unilateral injections of $2 \%$ Evans blue solution $(0.2 \mu \mathrm{L} /$ site $)$ into the $\mathrm{CeA}$, were deeply anesthetized with sodium thiopental (80 $\mathrm{mg} / \mathrm{kg}$ body weight) and perfused transcardially with isotonic $\mathrm{NaCl}$ followed by $10 \%$ formalin. The brain was removed, fixed in $10 \%$ formalin, frozen, cut in $50-\mu$ m coronal sections, stained with Nissl (cresyl violet) and analyzed by light microscopy (Axioskope 35M, Zeiss) to verify the injection site into the CeA.

Blood volume expansion

Twenty-four hours before the experiment, rats anesthe- 
tized with 2,2,2-tribromoethanol (200 $\mathrm{mg} / \mathrm{kg}$ body weight) had a catheter inserted into the right external jugular vein and placed in the right atrium, as previously described (19). On the day of the experiment, extracellular volume expansion was performed in conscious, freely moving rats by an intravenous injection of isotonic $(0.15 \mathrm{M})$ or hypertonic $(0.30$ M) $\mathrm{NaCl}$ solution ( $2 \mathrm{~mL} / 100$ body weight) over $1 \mathrm{~min}$.

Determination of sodium excretion and urinary volume

Urinary sodium concentration was determined by flame photometry (Micronal Model b 262, Brazil). The rates of urinary sodium excretion were calculated by multiplying the urinary sodium concentration times the urinary volume and expressed as $\mu \mathrm{Eq} / 100 \mathrm{~g}$ body weight. Urinary volume was expressed as $\mathrm{mL} / 100 \mathrm{~g}$ body weight.

\section{Determination of plasma ANP and OT concentrations}

Plasma levels of ANP and OT were measured by radioimmunoassay as previously described $(20,21)$. OT was extracted from $1 \mathrm{~mL}$ of plasma with acetone and petroleum ether, and ANP was extracted from $1 \mathrm{~mL}$ of plasma using Sep-Pak C-18 cartridges (Waters Corporation, USA). The percentages of recovery after extraction were 85 and $90 \%$ for OT and ANP, respectively. The assay sensitivity and intra- and interassay coefficients of variation were $0.9 \mathrm{pg} / \mathrm{mL}, 7.0$ and $12.6 \%$ for OT, and $7.0 \mathrm{pg} / \mathrm{mL}$, 6.0 and $10 \%$ for ANP.

\section{Drugs}

Muscimol (Tocris, Cookson, USA) was dissolved in isotonic saline and bicuculline (Research Biomedicals Inc., USA) was dissolved in a mix of propylene glycol/water $(2: 1)$. The doses of muscimol and bicuculline used in the present study were selected based on a previous study (22). The CeA injections were performed using a 10- $\mu \mathrm{L}$ Hamilton syringe connected by polyethylene tubing (PE$10)$ to an injector needle ( $0.3 \mathrm{~mm} O D)$. The injector needle was $2 \mathrm{~mm}$ longer than the guide cannula. Each rat received only one CeA treatment.

\section{Statistical analysis}

Data are reported as means \pm SEM. Renal and hormonal responses were analyzed by two-way analysis of variance (ANOVA) followed by the post hoc Newman Keuls test, using treatment (drugs) and time as factors. Statistical analysis was performed using the Sigma Stat computer program, with differences considered significant at $\mathrm{P}<$ 0.05 .

Experimental protocol

Experiment 1. Effect of GABA agonist or antagonist injection into the $\mathrm{CeA}$ on urinary sodium and water excretion induced by BVE. Rats had access to water, but not food, for $12 \mathrm{~h}$ before starting the experiment. After this period, the animals were weighed and received one intragastric water load $\left(37^{\circ} \mathrm{C}, 5 \%\right.$ body weight) in order to maintain constant urine flow. The animals then received a unilateral CeA injection of muscimol $(0.2 \mathrm{nmol})$, bicuculline $(1.6 \mathrm{nmol})$ or isotonic saline in a volume of $0.2 \mu \mathrm{L}$. For these injections, the rats were removed from their home cages and the injection cannula was introduced into the guide cannula. The injection took $60 \mathrm{~s}$. The animals were then placed in individual metabolic cages without access to food or water. Twenty minutes after the CeA injections, rats were subjected to isotonic or hypertonic extracellular volume expansion. Two urine samples were collected at 20-min intervals, starting immediately after extracellular volume expansion. Complete voiding of urine was manually induced by gently pressing the suprapubic region of the animal at the end of each interval. The same CeA treatments were performed in control animals that received one water load without blood volume expansion.

Experiment 2. Effects of GABA agonist or antagonist injection into the $\mathrm{CeA}$ on ANP and OT plasma levels induced by $B V E$. In this experiment, isotonic or hypertonic BVE was performed in animals injected unilaterally into the $\mathrm{CeA}$ with vehicle, muscimol $(0.2 \mathrm{nmol} / 0.2 \mu \mathrm{L})$ or bicuculline $(1.6 \mathrm{nmol} / 0.2 \mu \mathrm{L})$ as described in Experiment 1. Five minutes after BVE, unanesthetized rats were decapitated and trunk blood was collected into chilled plastic tubes containing heparin for OT determination, or EDTA $(10 \mu \mathrm{g} /$ $\mathrm{mL}$ ) and proteolytic enzyme inhibitors $(20 \mu \mathrm{L} 1 \mathrm{mM}$ phenylmethylsulfonyl fluoride and $20 \mu \mathrm{L} 500 \mu \mathrm{M}$ pepstatin A) for the determination of ANP. Blood samples were collected 5 min after BVE because peak hormone levels occur around this time (23). The same CeA treatments were performed in control animals without BVE.

\section{Results}

Histological analysis of the CeA

In Figure 1, plate A shows a photomicrograph of a Nissl-stained section through the $\mathrm{CeA}$ and plate $\mathrm{B}$ shows the correct cannula placement in the $\mathrm{CeA}$ reaching the lateral, medial and capsular portions of the CeA, corresponding to $-2.56 \mathrm{~mm}$ from bregma according to the coordinates described in the Paxinos and Watson Atlas (24).

Effect of GABA agonist or antagonist injection into the CeA on urinary sodium and water excretion induced by BVE

In rats not subjected to isotonic or hypertonic BVE that received muscimol, bicuculline or vehicle into the $\mathrm{CeA}$, 


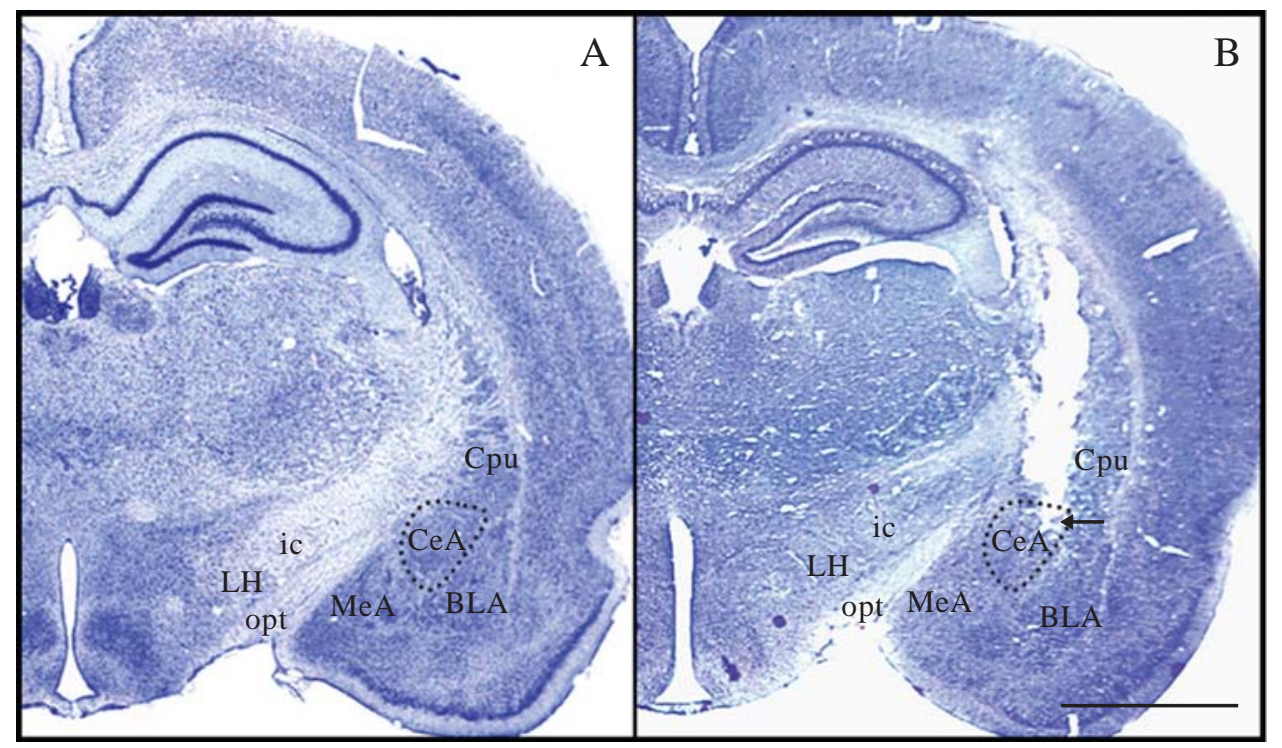

Figure 1. $A$, Photomicrograph of a representative Nissl-stained section through the central amygdaloid nucleus (CeA) corresponding to $-2.56 \mathrm{~mm}$ from the bregma according to the Atlas of Paxinos and Watson (24); $B$, Photomicrograph showing the injection site into the $\mathrm{CeA}$ (arrow) at the same level as $A$. BLA = basolateral amygdaloid nucleus; $\mathrm{Cpu}=$ caudate putamen/striatum; ic $=$ internal capsule; $\mathrm{LH}=$ lateral hypothalamic area; $\mathrm{MeA}=$ medial amygdaloid nucleus; opt $=$ optic tract. Bar: $3 \mathrm{~mm}$.

two-way ANOVA showed no significant difference in main effects between treatments for sodium excretion and urinary volume (Figure 2A-D).

In rats pretreated with vehicle into the $\mathrm{CeA}$, there was an increase of sodium excretion (Figure $2 \mathrm{~A}$ and $\mathrm{B}$ ) and urinary volume (Figure $2 \mathrm{C}$ and $\mathrm{D}$ ) following isotonic BVE (sodium excretion: $4.8 \pm 0.2 \mu \mathrm{Eq} \cdot 100 \mathrm{~g} \mathrm{~g}^{-1} \cdot 40 \mathrm{~min}^{-1}, \mathrm{~N}=8 \mathrm{vs}$ control: $0.5 \pm 0.2 \mu \mathrm{Eq} \cdot 100 \mathrm{~g} \mathrm{~g}^{-1} \cdot 40 \mathrm{~min}^{-1}, \mathrm{~N}=8$; urinary volume: $152 \pm 10.5 \mu \mathrm{L} \cdot 100 \mathrm{~g} \mathrm{~g}^{-1} .40 \mathrm{~min}^{-1}, \mathrm{~N}=8$ vs control: 60 $\pm 9.1 \mu \mathrm{L} \cdot 100 \mathrm{~g}^{-1} \cdot 40 \mathrm{~min}^{-1}, \mathrm{~N}=8$ ) and hypertonic BVE (sodium excretion: $8.7 \pm 0.6 \mu \mathrm{Eq} \cdot 100 \mathrm{~g} \mathrm{~g}^{-1} \cdot 40 \mathrm{~min}^{-1}, \mathrm{~N}=8$; urinary volume: $255.6 \pm 16.5 \mu \mathrm{L} \cdot 100 \mathrm{~g} \mathrm{~g}^{-1} .40 \mathrm{~min}^{-1}, \mathrm{~N}=8$ ).

Unilateral injections of muscimol into the $\mathrm{CeA}$ reduced the increase in sodium excretion after isotonic $(2.4 \pm 0.3$ $\left.\mu \mathrm{Eq} \cdot 100 \mathrm{~g} \mathrm{~g}^{-1} \cdot 40 \mathrm{~min}^{-1}, \mathrm{~N}=6\right)$ or hypertonic BVE $(4.0 \pm 0.7$ $\mu \mathrm{Eq} \cdot 100 \mathrm{~g}^{-1} \cdot 40 \mathrm{~min}^{-1}, \mathrm{~N}=6$ ) in comparison to vehicletreated group (Figure $2 \mathrm{~A}$ and $\mathrm{B}$ ). In addition, pretreatment with muscimol into the $\mathrm{CeA}$ induced a decrease of urine output after hypertonic BVE $\left(83.8 \pm 10 \mu \mathrm{L} \cdot 100 \mathrm{~g}^{-1} \cdot 40 \mathrm{~min}^{-1}\right.$, $\mathrm{N}=6$ ) and produced no changes in response to isotonic BVE (Figure $2 \mathrm{C}$ and $\mathrm{D}$ ). In rats pretreated with bicuculline into the $\mathrm{CeA}$, there was a decrease in urine output after isotonic (98.8 $\left.\pm 14.4 \mu \mathrm{L} \cdot 100 \mathrm{~g} \mathrm{~g}^{-1} \cdot 40 \mathrm{~min}^{-1}, \mathrm{~N}=6\right)$ and hypertonic BVE (154 $\left.\pm 10 \mu \mathrm{L} \cdot 100 \mathrm{~g} \mathrm{~g}^{-1} \cdot 40 \mathrm{~min}^{-1}, \mathrm{~N}=6\right)$ compared to the vehicle-treated group (Figure $2 \mathrm{C}$ and $\mathrm{D}$ ). In regard to sodium excretion, bicuculline did not affect the natriuresis induced by isotonic or hypertonic BVE.
Effect of GABA agonist or antagonist injection into the $C e A$ on plasma ANP and OT levels induced by $B V E$. In rats not subjected to isotonic or hypertonic BVE that received muscimol, bicuculline or vehicle into the CeA, two-way ANOVA showed no significant main effects between treatments for plasma ANP and OT levels (Figure 3A-D).

In rats pretreated with vehicle into the $\mathrm{CeA}$, there was an increase of plasma OT (Figure $3 \mathrm{~A}$ and $\mathrm{B}$ ) and ANP (Figure $3 \mathrm{C}$ and $\mathrm{D}$ ) concentrations following isotonic $\mathrm{BVE}$ (OT: $19.3 \pm 1 \mathrm{pg} / \mathrm{mL}, \mathrm{N}=8$ vs control: $8.8 \pm 1.2 \mathrm{pg} / \mathrm{mL}, \mathrm{N}=$ 6); ANP: $(258.3 \pm 28.1 \mathrm{pg} / \mathrm{mL}, \mathrm{N}=8$ vs control: $65.3 \pm 14$ $\mathrm{pg} / \mathrm{mL}, \mathrm{N}=6$ ) and hypertonic BVE (OT: $48 \pm 3 \mathrm{pg} / \mathrm{mL}, \mathrm{N}=$ 8; ANP: $318 \pm 16.3 \mathrm{pg} / \mathrm{mL}, \mathrm{N}=8$ ).

Unilateral $\mathrm{CeA}$ injections of muscimol induced a decrease of plasma OT levels in response to isotonic or hypertonic BVE $(15.3 \pm 0.6 \mathrm{pg} / \mathrm{mL}, \mathrm{N}=8$ and $26.5 \pm 2.6 \mathrm{pg} /$ $\mathrm{mL}, \mathrm{N}=8$, respectively; Figure $3 \mathrm{~A}, \mathrm{~B}$ ) compared to the vehicle-treated group. In addition, plasma ANP concentration was also reduced in response to isotonic $(97 \pm 12.8 \mathrm{pg} /$ $\mathrm{mL}, \mathrm{N}=8$; Figure $3 \mathrm{C})$ and hypertonic BVE (160 $\pm 14.6 \mathrm{pg} /$ $\mathrm{mL}, \mathrm{N}=8$; Figure 3D).

Bicuculline into the CeA decreased plasma ANP in rats subjected to isotonic $(167 \pm 12 \mathrm{pg} / \mathrm{mL}, \mathrm{N}=8)$ or hypertonic $(209.7 \pm 14.6 \mathrm{pg} / \mathrm{mL}, \mathrm{N}=8)$ BVE (Figure $3 \mathrm{C}$ and D). On the other hand, bicuculline into the $\mathrm{CeA}$ increased the effects of hypertonic blood volume expansion on plasma OT levels $(60 \pm 2.6 \mathrm{pg} / \mathrm{mL}, \mathrm{N}=8$; Figure $3 \mathrm{~B})$. 

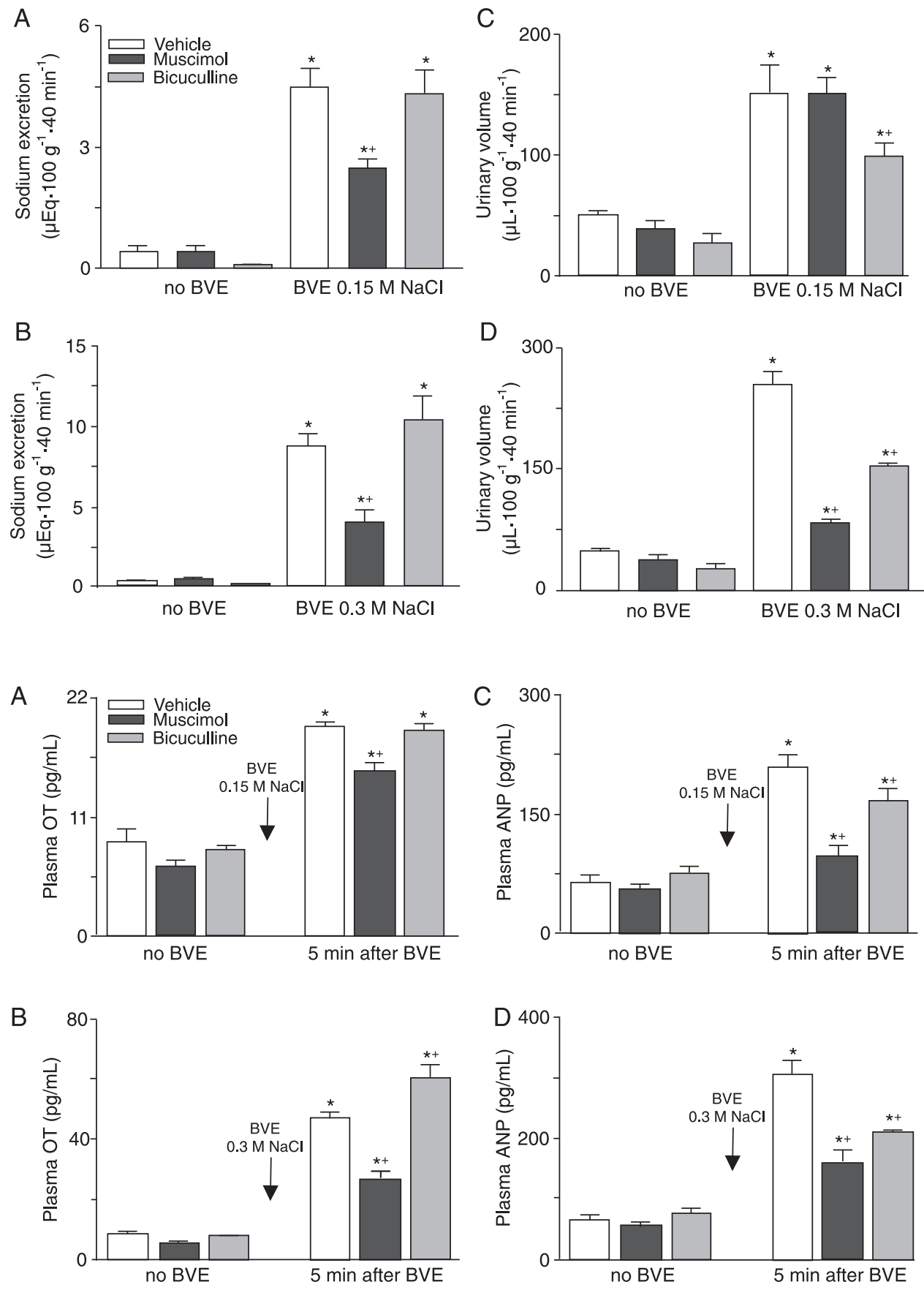

Figure 2. Sodium excretion $(A, B)$ and urinary volume $(C$, $D$ ) in rats that received an injection of vehicle $(\mathrm{N}=8)$, muscimol $(0.2 \mathrm{nmol} / 0.2 \mu \mathrm{L}$, $\mathrm{N}=6-8)$ or bicuculline (1.6 $\mathrm{nmol} / 0.2 \mu \mathrm{L}, \mathrm{N}=6-7$ ) into the central amygdaloid nucleus and were subjected or not to isotonic or hypertonic blood volume expansion (BVE). Data are reported as means \pm SEM. ${ }^{*} P<0.05$ vs control + vehicle; ${ }^{+} \mathrm{P}<0.05$ vs BVE + vehicle (two-way ANOVA followed by the post hoc Newman Keuls test).
Figure 3. Plasma levels of oxytocin (OT; $A, B)$ and atrial natriuretic peptide (ANP; C, $D)$ in rats that received an injection of vehicle $(\mathrm{N}=6-8)$, muscimol $(0.2 \mathrm{nmol} / 0.2 \mu \mathrm{L}, \mathrm{N}$ $=6-8)$ or bicuculline (1.6 $\mathrm{nmol} / 0.2 \mu \mathrm{L}, \mathrm{N}=6-8$ ) into the central amygdaloid nucleus and were subjected or not to isotonic or hypertonic blood volume expansion (BVE). Data are reported as means \pm SEM. ${ }^{*} \mathrm{P}<0.05$ vs control + vehicle; ${ }^{+} \mathrm{P}<0.05$ vs $\mathrm{BVE}+$ vehicle (two-way ANOVA followed by the post hoc Newman Keuls test).

\section{Discussion}

The present results show that sodium excretion, plasma OT and ANP levels induced by isotonic or hypertonic BVE were reduced in rats pretreated with the GABAergic agonist muscimol in the CeA. Additionally, it was observed that muscimol injection into the CeA significantly reduced urine output in rats subjected to hypertonic BVE. Based on the data obtained, we propose that the reduction of plasma ANP and OT levels after injection of muscimol into the CeA may contribute to the reduced sodium excretion after isoor hypertonic BVE. In spite of unilateral injection of musci- 
mol, bicuculline and vehicle into the CeA, the present data show significant hormonal responses and urinary excretion results in response to iso- or hypertonic BVE. Thus, it is reasonable to consider that bilateral $\mathrm{CeA}$ treatment probably would induce more pronounced effects.

It is well known that OT is synthesized within the neurons of the supraoptic (SON) and paraventricular nucleus (PVN) in the hypothalamus and is released into the circulation from the nerve endings in the neurohypophysis. Previous studies $(3,25)$ have shown that the stimulation of OT secretion could be induced by activation of intrahypothalamic ANPergic terminals. These, in turn, would induce the synthesis and central release of ANP that would activate the neurohypophysis release of OT. Once released into the circulation, OT induces the cardiac release of ANP, leading to diuresis, natriuresis and vasodilatation to reestablish body fluid homeostasis. Natriuresis induced by extracellular volume expansion is mediated by ANP and OT release $(2,3,26)$, both of them circulate to the kidney and act on renal specific receptors to reduce the sodium reabsorption by a nitric oxide-cGMP mechanism $(3,27)$.

Our findings suggest that, in response to BVE, muscimol injected into the $\mathrm{CeA}$ inhibits synaptic inputs mediated by perinuclear GABAergic interneurones located around the PVN and SON. It is reasonable to assume that the oxytocinergic magnocellular neurons in the PVN and SON receive these local GABAergic inhibitory inputs, leading to a decrease of plasma OT and ANP release and the consequent sodium excretion in response to iso- or hypertonic BVE.

Decavel and Van den Pol (17) suggested that GABA is the most important inhibitory neurotransmitter in the magnocellular system. However, relatively few studies have shown that inhibitory amino acids (i.e., GABA) mediate all fast synaptic transmission in the magnocellular neuroendocrine system (28). Saridaki et al. (29), using the neurosecretosome perfusion model in rats, showed an inhibitory action of muscimol on oxytocin release from neurohypophyseal neurosecretory terminals that was reversed by bicuculline, providing evidence for a direct effect on $\mathrm{GABA}_{\mathrm{A}}$ receptors at the posterior pituitary neurosecretosome terminals. Similarly, using a microdialysis study, Engelmann et al. (30) showed a GABAergic selective inhibition of the secretory and basal electrical activity of putative OT neurons in the SON, while bicuculline stimulated the release of OT within the SON and into the blood. Other investigators (31) verified the possibility that the GABA system might inhibit the release of oxytocin, by measuring milk-ejection responses and urinary output following icv hypertonic saline administration in lactating rats. It was shown that oxytocin release, as well as the pressor response, were blocked by icv injection of GABA and muscimol, which was due to central sympathetic stimulation. The present data agree with the notion that GABAergic circuits mediate inhibitory inputs to magnocellular neurons in the PVN and SON, and further expand the understanding of the participation of limbic structures within these circuits, as proposed by Tasker and Dudek (32).

We have previously shown (11) the morphofunctional interrelationship between the lateral parabrachial nucleus cells and specific afferent forebrain neuronal groups of cells (including CeA, BNST and PVN) that are activated after an isotonic BVE. As a result of this activated pathway, BVE increases the release of OT and ANP into the blood (10). Thus, taking into account the previous and current data, it can be hypothesized that the CeA pathways stimulate ANP and OT secretion in the PVN, since it has been shown that these structures are reciprocally connected $(33,34)$ and the CeA GABAergic blockade reduces these responses. In addition, the $\mathrm{CeA}$ is also reciprocally connected with the lateral part of the BNST, both structures being major components of the central extended amygdala complex (35). The BNST GABA-producing neurons (36) project to the PVN (37) and receive projections from more distal limbic structures as well as from brainstem A1 noradrenergic neurons and peptidergic afferents from the hypothalamus. Since the central extended amygdala complex is reciprocally connected with the hypothalamus, an integrative site of neuroendocrine and autonomic functions (34), it is plausible to consider the existence of a CeA GABAergic system that integrates a neural network involved in fluid balance control.

In the present study, bicuculline injection into the CeA specifically regulated urinary volume and did not affect sodium excretion in response to iso- or hypertonic BVE. Voisin et al. (38), using urethane-anesthetized rats, reported that icv or bilateral microinfusions of both muscimol and bicuculline into the SON inhibited the milk ejection reflex, probably by inhibition of the electrical activity of oxytocinergic neurons. In view of these results, it can be suggested that bicuculline inhibitory modulation through $\mathrm{GABA}_{\mathrm{A}}$ receptors may be either the same as that of muscimol or may arise from the disinhibition of local inhibitory neurons innervating magnocellular oxytocinergic neurons in the hypothalamus, while muscimol may inhibit PVN/ SON oxytocinergic neurons directly. Further studies will be necessary to understand the complex mechanism involving the blockade of $\mathrm{GABA}_{\mathrm{A}}$ receptors in the pattern of the acute stimulus of BVE.

Water and sodium excretion are affected by changes in arterial blood pressure. In the absence of blood pressure determination in the present study, we cannot assure the 
contribution or not of hemodynamic changes in water and sodium excretion. However, Goren et al. (39) have demonstrated that $\mathrm{GABA}_{\mathrm{A}}$ receptors located in the CeA do not have and essential role in cardiovascular regulation. These investigators showed that bicuculline injection into the CeA produced a slight increase in blood pressure (3 min at least, which returned to basal levels and did not change heart rate). In addition, microinjections of GABA agonists into the $\mathrm{CeA}$ of awake rats did not elicit cardiovascular responses (40).

Taken together, the present results represent the first evidence to suggest that the GABAergic system in the central amygdaloid nucleus modulates the physiological mechanisms involved in the control of urine electrolyte and hormone release in rats submitted to changes in extracellular volume and plasma osmolality. These results suggest the involvement of a GABAergic CeA system in a neural circuit that controls body fluid homeostasis in response to isotonic and hypertonic BVE.

\section{Acknowledgments}

The authors thank Marina Holanda, Maria Valci Silva, and Rubens de Mello for excellent technical assistance.

\section{References}

1. Pettersson A, Ricksten SE, Towle AC, Hedner J, Hedner T. Haemodynamics and plasma ANP (atrial natriuretic peptide) after acute blood volume expansion in normotensive and spontaneously hypertensive rats. Acta Physiol Scand 1988; 133: 513-518.

2. Antunes-Rodrigues $\mathrm{J}$, Machado $\mathrm{BH}$, Andrade HA, Mauad $H$, Ramalho MJ, Reis LC, et al. Carotid-aortic and renal baroreceptors mediate the atrial natriuretic peptide release induced by blood volume expansion. Proc Natl Acad Sci U S A 1992; 89: 6828-6831.

3. Haanwinckel MA, Elias LK, Favaretto AL, Gutkowska J, McCann SM, Antunes-Rodrigues J. Oxytocin mediates atrial natriuretic peptide release and natriuresis after volume expansion in the rat. Proc Natl Acad Sci U S A 1995; 92: 79027906.

4. Gelsema AJ, McKitrick DJ, Calaresu FR. Cardiovascular responses to chemical and electrical stimulation of amygdala in rats. Am J Physiol 1987; 253: R712-R718.

5. Saha S. Role of the central nucleus of the amygdala in the control of blood pressure: descending pathways to medullary cardiovascular nuclei. Clin Exp Pharmacol Physiol 2005; 32: 450-456.

6. Galeno TM, Van Hoesen GW, Maixner W, Johnson AK, Brody MJ. Contribution of the amygdala to the development of spontaneous hypertension. Brain Res 1982; 246: 1-6.

7. Gentil CG, Peres VL, Tufik S, Antunes-Rodrigues J, Covian MR. Effects of electrical and chemical stimulation of the central nervous system on sodium chloride and water intake. Acta Physiol Lat Am 1973; 23: 475-476.

8. Galaverna O, De Luca LA Jr, Schulkin J, Yao SZ, Epstein AN. Deficits in $\mathrm{NaCl}$ ingestion after damage to the central nucleus of the amygdala in the rat. Brain Res Bull 1992; 28: 89-98.

9. Zardetto-Smith AM, Beltz TG, Johnson AK. Role of the central nucleus of the amygdala and bed nucleus of the stria terminalis in experimentally-induced salt appetite. Brain Res 1994; 645: 123-134.

10. Godino A, Giusti-Paiva A, Antunes-Rodrigues J, Vivas L. Neurochemical brain groups activated after an isotonic blood volume expansion in rats. Neuroscience 2005; 133: 493-505.

11. Margatho LO, Godino A, Oliveira FR, Vivas L, Antunes-

Rodrigues J. Lateral parabrachial afferent areas and serotonin mechanisms activated by volume expansion. $J$ Neurosci Res 2008; 86: 3613-3621.

12. Sun AY, Li DX. Cardiovascular responses to intracerebroventricular injection of GABA in renovascular hypertensive rats. Zhongguo Yao Li Xue Bao 1994; 15: 136-138.

13. Davis M, Rainnie D, Cassell M. Neurotransmission in the rat amygdala related to fear and anxiety. Trends Neurosci 1994; 17: $208-214$

14. Ciriello J, Roder S. GABAergic effects on the depressor responses elicited by stimulation of central nucleus of the amygdala. Am J Physiol 1999; 276: H242-H247.

15. McCann SM, Rettori V. Gamma aminobutyric acid (GABA) controls anterior pituitary hormone secretion. In: Racagni G, Donoso AO (Editors), GABA and endocrine function. New York: Raven Press; 1986. p 173-189.

16. Oertel WH, Mugnaini E, Tappaz ML, Weise VK, Dahl AL, Schmechel DE, et al. Central GABAergic innervation of neurointermediate pituitary lobe: biochemical and immunocytochemical study in the rat. Proc Natl Acad Sci U S A 1982; 79: 675-679.

17. Decavel C, Van den Pol AN. GABA: a dominant neurotransmitter in the hypothalamus. J Comp Neurol 1990; 302: 1019-1037.

18. Negoro H, Visessuwan S, Holland RC. Inhibition and excitation of units in paraventricular nucleus after stimulation of the septum, amygdala and neurohypophysis. Brain Res 1973; 57: 479-483.

19. Harms PG, Ojeda SR. A rapid and simple procedure for chronic cannulation of the rat jugular vein. J Appl Physiol 1974; 36: 391-392.

20. Elias LL, Antunes-Rodrigues J, Elias PC, Moreira AC. Effect of plasma osmolality on pituitary-adrenal responses to corticotropin-releasing hormone and atrial natriuretic peptide changes in central diabetes insipidus. J Clin Endocrinol Metab 1997; 82: 1243-1247.

21. Gutkowska J, Horky K, Thibault G, Januszewicz P, Cantin $\mathrm{M}$, Genest J. Atrial natriuretic factor is a circulating hormone. Biochem Biophys Res Commun 1984; 125: 315-323.

22. Callera JC, Oliveira LB, Barbosa SP, Colombari DS, De Luca LA Jr, Menani JV. GABA(A) receptor activation in the lateral parabrachial nucleus induces water and hypertonic 
$\mathrm{NaCl}$ intake. Neuroscience 2005; 134: 725-735.

23. Eskay R, Zukowska-Grojec Z, Haass M, Dave JR, Zamir N. Circulating atrial natriuretic peptides in conscious rats: regulation of release by multiple factors. Science 1986; 232: 636-639.

24. Paxinos G, Watson C. The rat brain in stereotaxic coordinates. 2nd edn. New York: Academic Press; 1997.

25. Chriguer RS, Rocha MJ, Antunes-Rodrigues J, Franci CR. Hypothalamic atrial natriuretic peptide and secretion of oxytocin. Brain Res 2001; 889: 239-242.

26. Reis LC, Ramalho MJ, Favaretto AL, Gutkowska J, McCann $\mathrm{SM}$, Antunes-Rodrigues J. Participation of the ascending serotonergic system in the stimulation of atrial natriuretic peptide release. Proc Natl Acad Sci U S A 1994; 91: 1202212026.

27. Soares TJ, Coimbra TM, Martins AR, Pereira AG, Carnio EC, Branco LG, et al. Atrial natriuretic peptide and oxytocin induce natriuresis by release of cGMP. Proc Natl Acad Sci U S A 1999; 96: 278-283.

28. Gribkoff VK, Dudek FE. Effects of excitatory amino acid antagonists on synaptic responses of supraoptic neurons in slices of rat hypothalamus. J Neurophysiol 1990; 63: 60-71.

29. Saridaki E, Carter DA, Lightman SL. Gamma-aminobutyric acid regulation of neurohypophysial hormone secretion in male and female rats. $J$ Endocrinol 1989; 121: 343-349.

30. Engelmann M, Bull PM, Brown $\mathrm{CH}$, Landgraf R, Horn TF, Singewald N, et al. GABA selectively controls the secretory activity of oxytocin neurons in the rat supraoptic nucleus. Eur J Neurosci 2004; 19: 601-608.

31. Bisset GW, Chowdrey HS, Fairhall KM, Gunn LK. Central inhibition by gamma-aminobutyric acid and muscimol of the release of vasopressin and oxytocin by an osmotic stimulus in the rat. Br J Pharmacol 1990; 99: 529-535.

32. Tasker JG, Dudek FE. Local inhibitory synaptic inputs to neurones of the paraventricular nucleus in slices of rat hypothalamus. J Physiol 1993; 469: 179-192.

33. Gray TS, Carney ME, Magnuson DJ. Direct projections from the central amygdaloid nucleus to the hypothalamic paraventricular nucleus: possible role in stress-induced adrenocorticotropin release. Neuroendocrinology 1989; 50: 433446.

34. Swanson LW, Sawchenko PE. Hypothalamic integration: organization of the paraventricular and supraoptic nuclei. Annu Rev Neurosci 1983; 6: 269-324.

35. Veinante $P$, Freund-Mercier MJ. Intrinsic and extrinsic connections of the rat central extended amygdala: an in vivo electrophysiological study of the central amygdaloid nucleus. Brain Res 1998; 794: 188-198.

36. Cullinan WE, Herman JP, Watson SJ. Ventral subicular interaction with the hypothalamic paraventricular nucleus: evidence for a relay in the bed nucleus of the stria terminalis. J Comp Neurol 1993; 332: 1-20.

37. Roland BL, Sawchenko PE. Local origins of some GABAergic projections to the paraventricular and supraoptic nuclei of the hypothalamus in the rat. J Comp Neurol 1993; 332: 123-143.

38. Voisin DL, Herbison AE, Poulain DA. Central inhibitory effects of muscimol and bicuculline on the milk ejection reflex in the anaesthetized rat. J Physiol 1995; 483 (Part 1): 211224.

39. Goren Z, Aslan N, Berkman K, Oktay S, Onat F. The role of amygdala and hypothalamus in GABAA antagonist bicuculline-induced cardiovascular responses in conscious rats. Brain Res 1996; 722: 118-124.

40. Sanders SK, Shekhar A. Blockade of GABAA receptors in the region of the anterior basolateral amygdala of rats elicits increases in heart rate and blood pressure. Brain Res 1991; 567: 101-110. 